\title{
Mutation analysis of peroxisome proliferator-activated receptor- $\gamma$ coactivator-1 (PGC-1) and relationships of identified amino acid polymorphisms to Type II diabetes mellitus
}

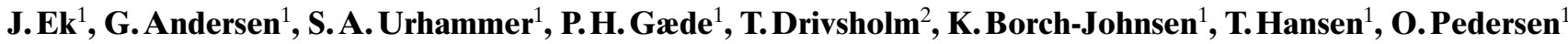 \\ ${ }^{1}$ Steno Diabetes Center and Hagedorn Research Institute, Gentofte, Copenhagen, Denmark \\ ${ }^{2}$ Centre of Preventive Medicine, Glostrup University Hospital, Denmark
}

\begin{abstract}
Aim/hypothesis. This study aimed to investigate if variability in the peroxisome proliferator-activated receptor- $\gamma$ coactivator-1 (PGC-1) gene is associated with Type II (non-insulin-dependent) diabetes mellitus.

Methods. The PGC-1 gene was examined in 53 Type II diabetic patients applying single strand conformational polymorphism analysis followed by nucleotide sequencing. Identified variants were genotyped in an association study comprising 483 Type II diabetic patients and 216 glucose-tolerant control subjects. A replication study was done in an additional 201 Type II diabetic patients and 293 glucose-tolerant subjects. Furthermore, a potential interaction between the Pro12Ala polymorphism of PPAR- $\gamma 2$ and the PGC1 Gly482Ser variant on risk of Type II diabetes was investigated.

Results. A total of seven variants (Ser74Leu, IVS2 + 52C $\rightarrow$ A, Thr394Thr, Asp475Asp, Gly482Ser,
\end{abstract}

Thr528Thr, and Thr612Met) were identified and investigated in an association study. Six of the variants showed no association with Type II diabetes in the initial study. However, the Gly482Ser polymorphism, was more frequent among Type II diabetic patients $(37.0 \%)$ than among glucose-tolerant subjects $(30.8 \%)(p=0.032)$. In a replication study the difference in allele frequencies of the Gly482Ser variant remained significant $(p=0.0135)$. The combined study yielded an allele frequency of $37.3 \%$ (34.7-39.9) for Type II diabetic patients and $30.5 \%$ (27.7-33.4) for glucose-tolerant subjects $(p=0.0007)$. No interaction between this variant and the Pro12Ala polymorphism of PPAR- $\gamma 2$ was observed.

Conclusion/interpretation. A widespread Gly482Ser polymorphism of $P G C-1$ is associated with a 1.34 genotype relative risk of Type II diabetes. [Diabetologia (2001) 44: 2220-2226]

Keywords PPAR- $\gamma$ coactivator- 1 , mutations, Type II diabetes, genetic epidemiology, association study.
Peroxisome proliferator-activated receptor- $\gamma$ coactivator-1 (PGC-1) is a novel transcriptional co-activator of a series of nuclear receptors including peroxi-

Received: 4 April 2001 and in revised form: 19 July 2001

Corresponding author: Oluf Pedersen, Professor, M.D., D.M.Sc., Steno Diabetes Center, Niels Steensens Vej 2, DK-2820 Gentofte, Copenhagen, Denmark,

E-mail: oluf.p@dadlnet.dk

Abbreviations: PPAR, peroxisome proliferator-activated receptor; PGC-1, PPAR- $\gamma$ coactivator-1; MEF2C, myocyte enhancer factor $2 \mathrm{C}$; OHA, oral hypoglycaemic agent; SSCP, single strand conformational polymorphism; GRR, genotype relative risk. some proliferator-activated receptor- $\gamma(\operatorname{PPAR}-\gamma)$, a transcription factor involved in adipogenesis and a functional receptor for thiazolidinediones [1, 2]. Similarly, $P G C-1$ is a coactivator of peroxisome proliferator-activated receptor- $\alpha$ (PPAR- $\alpha$ ), which plays a key role in the transcriptional control of genes encoding mitochondrial fatty acid beta-oxidation enzymes [3]. Studies in cultured muscle-cell lines show that PGC-1 stimulates mitochondrial biogenesis and respiration through an induction of uncoupling protein 2 and through regulation of the nuclear respiratory factors [2]. Thus, PGC-1 is a key factor in the stimulation of adaptive thermogenesis, e.g. during high caloric diets or cold exposure. It has recently 
been shown that PGC-1 by binding to myocyte enhancer factor 2C (MEF2C) also controls the expression of the endogenous glucose transporter (GLUT4) gene in muscle cells [4]. In humans PGC-1 is expressed in high quantities in liver, heart, kidney, and skeletal muscle and to a lesser extent in white adipose tissue, pancreas, and brain [5,6]. Given the critical roles of PGC-1 in several aspects of adipogenesis, oxidative metabolism, thermogenesis and glucose uptake and the fact that human $P G C-1$ is mapped to a chromosomal region (4p15.1) that in Pima Indians has been shown to be linked to fasting serum insulin concentrations [7] we hypothesized that variability in the $P G C-1$ gene confers susceptibility to Type II diabetes. This study reports the results of the mutation analysis of the entire coding region of the $P G C-1$ gene and the identification of a widespread amino acid polymorphism, which is reproducibly associated with Type II diabetes among Danish Caucasians.

\section{Subjects and methods}

Subjects. Mutation analysis was completed in 53 Type II diabetic patients ( 30 men, 23 women) recruited from the outpatient clinic at Steno Diabetes Center. The age of the patients was $64 \pm 9$ years, age of diagnosis $57 \pm 9$ years, body mass in$\operatorname{dex}(\mathrm{BMI}) 29.7 \pm 4.9 \mathrm{~kg} / \mathrm{m}^{2}$, and $\mathrm{HbA}_{1 \mathrm{C}} 8.3 \pm 1.7 \%$ (means \pm SD). More than $70 \%$ of the patients fulfilled the 1998 WHO criteria for the metabolic syndrome [8], $31 \%$ of the patients were treated with diet alone, $65 \%$ with oral hypoglycaemic agents (OHA), and $4 \%$ with insulin alone or in combination with OHA.

The initial association studies were done in a group of unrelated Type II diabetic patients recruited from the outpatient clinic at Steno Diabetes Center during 1994-1997 and a group of unrelated glucose-tolerant subjects without a known family history of diabetes sampled at random during 1994-1997 from the Danish Central Population Register and all living in the same area of Copenhagen as the Type II diabetic patients. In the group of Type II diabetic patients $(n=483,278$ men, 205 women) the age was $61 \pm 11$ years, age of diagnosis $55 \pm 11$ years, BMI $29.0 \pm 5.3 \mathrm{~kg} / \mathrm{m}^{2}$, and $\mathrm{HbA}_{1 \mathrm{C}} 8.1 \pm 1.6 \%$. The patients were treated with diet alone $(27 \%)$, with OHA $(58 \%)$, or with insulin in combination with OHA $(15 \%)$. In the group of glucose tolerant subjects $(n=216,105 \mathrm{men}, 111$ women) the age was $52 \pm 14$ years, and BMI $25.3 \pm 3.8 \mathrm{~kg} / \mathrm{m}^{2}$.

The association study used for replication comprised unrelated Type II diabetic patients recruited from the outpatient clinic at Steno Diabetes Center during 1992-1993 and a population based sample of unrelated glucose-tolerant subjects without a known family history of diabetes born in 1936 and examined during 1996-1997 at the Copenhagen County Center of Preventive Medicine. In the group of Type II diabetic patients $(n=201$, 152 men, 49 women) the age was $55 \pm 7$ years, age of diagnosis $48 \pm 8$ years, BMI $29.8 \pm 4.4 \mathrm{~kg} / \mathrm{m}^{2}$, and $\mathrm{HbA}_{1 \mathrm{C}} 8.6 \pm 1.7 \%$. The patients were treated with diet alone (29\%), with OHA $(60 \%)$, or with insulin in combination with OHA (11\%). In the group of glucose-tolerant subjects $(n=293,134$ men, 159 women $)$ the age was $60.5 \pm 0.4$ years and BMI $26.2 \pm 3.7 \mathrm{~kg} / \mathrm{m}^{2}$.

Diabetes was diagnosed according to 1998 WHO criteria [8]. All glucose-tolerant subjects underwent a $75 \mathrm{~g}$ oral glu- cose tolerance test (OGTT). All participants were Danish Caucasians by self-report. Informed written consent was obtained from all subjects before participation. The study was approved by the Ethical Committee of Copenhagen and was in accordance with the principles of the Declaration of Helsinki II.

Biochemical assays. Blood samples for measurement of serum concentrations of insulin, total cholesterol, high-density lipoprotein (HDL) cholesterol, triglycerides and plasma glucose and non-esterified fatty acids (NEFA) were drawn after a 12 -h overnight fast. Serum triglycerides, total serum cholesterol, serum HDL-cholesterol, and plasma NEFA were analysed using enzymatic colorimetric methods (GPO-PAP and CHOD-PAP, Roche Molecular Biochemicals, Germany and NEFA C, Wako, Neuss, Germany). The plasma glucose concentration was analysed by a glucose oxidase method (Granutest, Merck, Darmstadt, Germany) and serum specific insulin (excluding des $(31,32)$ - and intact proinsulin) was measured by ELISA (Dako insulin kit K6219, Dako Diagnostics, Ely, UK). $\mathrm{HbA}_{1 \mathrm{C}}$ was measured by ion-exchange high performance liquid chromatography (nondiabetic reference range: $4.1-6.4 \%$ ).

Mutation analysis and genotyping. The genetic analyses were done on genomic DNA isolated from human leukocytes. The coding region of the PGC-1 gene (EMBL AF106698) including intron-exon boundaries (in total $3357 \mathrm{bp}$ ) was divided into 17 segments (sized 145-273 nucleotides) for SSCP and heteroduplex analysis. In our laboratory, this method has an estimated sensitivity of more than $95 \%$ for detecting a variety of known mutations. The segments also included the 5' untranslated sequence of $90 \mathrm{bp}$. Primer sequences are listed in Table 1. PCR amplification was carried out in a volume of $25 \mu \mathrm{l}$ containing $100 \mathrm{ng}$ genomic DNA, $1 \times \mathrm{PCR}$-buffer, $0.2 \mu \mathrm{mol} / 1 \mathrm{of}$ each primer, $0.2 \mathrm{mmol} / \mathrm{l} \mathrm{dNTP}, 10 \mathrm{mCi} / \mathrm{ml} \alpha-{ }^{32} \mathrm{P}-\mathrm{dCTP}, 0.6$ units AmpliTaq Gold polymerase (Perkin Elmer, Foster City, Calif., USA) and $\mathrm{MgCl}_{2}$ concentration as shown in Table 1 . The cycling programme was a denaturation step at $95^{\circ} \mathrm{C}$ for $15 \mathrm{~min}$ followed by 40 cycles of $94^{\circ} \mathrm{C}$ for $30 \mathrm{~s}$, annealing at $\mathrm{T}_{\text {anneal }}$ for $30 \mathrm{~s}$, and elongation at $72^{\circ} \mathrm{C}$ for $60 \mathrm{~s}$ with a final elongation step at $72^{\circ} \mathrm{C}$ for 9 min using a GeneAmp 9600 thermal cycler (Perkin Elmer). The annealing temperatures are listed in Table 1. SSCP was carried out at two different experimental settings as reported [9] and aberrantly migrating samples were sequenced using fluorescent chemistry (Dye Primer Cycle Sequencing Ready Reaction Kit, Applied Biosystems, Calif., USA). The Ser74Leu and IVS2 $+52 C \rightarrow A$ variants were genotyped by PCR with primers PC2F-PC2RNY followed by digestion with DraI and ApaI, respectively. The Thr394Thr variant was genotyped employing restriction site generating (RG) $\mathrm{PCR}\left(2 \mathrm{mmol} / \mathrm{l} \mathrm{MgCl}_{2}, \mathrm{~T}_{\text {anneal }} 55^{\circ} \mathrm{C}\right)$ with upstream RG-primer 5'-GCC AGT CAA TTA ATT CCA AAC C-3' (mismatched nucleotide is underlined) and downstream primer PC15R followed by digestion with HpaII. The Asp475Asp variant was genotyped using RG-PCR $\left(2 \mathrm{mmol} / \mathrm{l} \mathrm{MgCl}_{2}, \mathrm{~T}_{\text {anneal }} 59^{\circ} \mathrm{C}\right)$ with upstream RG-primer 5'-ATC CCA GTC AAG CTG TTT TTC T-3' and downstream RG-primer 5'-GAA GAA CAA GAA GGA GAC ACA TCG-3' followed by digestion with TaqI. The Gly482Ser variant was amplified with primers PC15F-PC17R and digested with HpaII. The Thr528Thr variant was genotyped using RG-PCR $\left(2 \mathrm{mmol} / \mathrm{l} \mathrm{MgCl}_{2}, \mathrm{~T}_{\text {anneal }}\right.$ $60^{\circ} \mathrm{C}$, upstream RG-primer 5'-GAC GAC GAA GCA GGC AAG-3', downstream primer 5'-GAT TTG GGT GGT GAC ACA GA-3') with subsequent digestion with Cac8I. The Thr612Met variant was amplified with primers PC8F-PC8R and digested with NlaIII. The Pro12Ala polymorphism of $P P A R-\gamma 2$ was genotyped by RG-PCR $\left(3 \mathrm{mmol} / 1 \mathrm{MgCl}_{2}, \mathrm{~T}_{\text {anneal }}\right.$ 
Table 1. Primer sequences and PCR conditions for mutational analysis of $P G C-1$

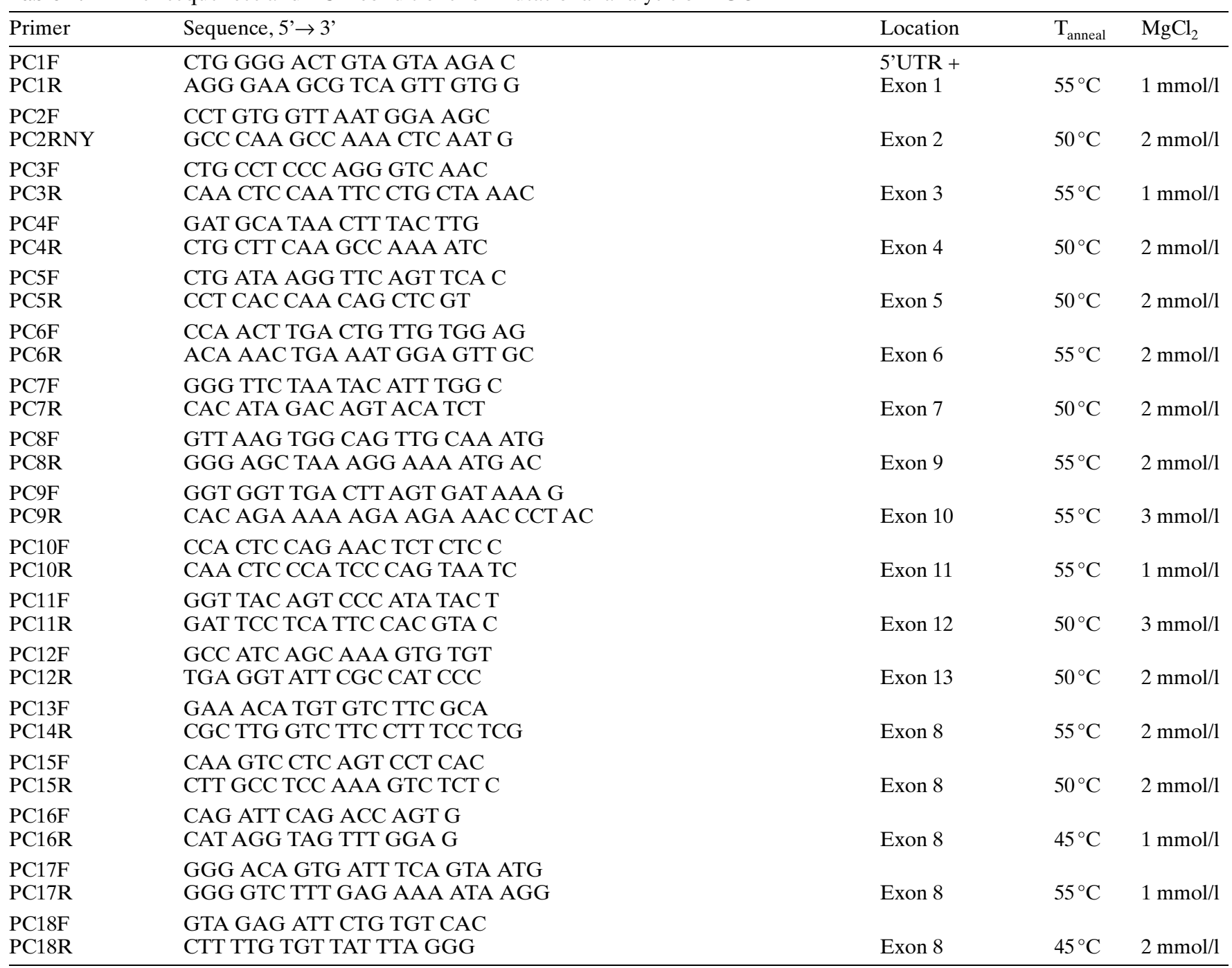

All forward primers were extended with a 21M13 tail for sequencing (TGT AAA ACG ACG GCC AGT) and all reverse primers with an M13 tail (CAG GAA ACA GCT AGT ACC)

$53^{\circ} \mathrm{C}$ ) with upstream primer 5'-CAA GCC CAG TCC TTT CTG TG-3' and downstream RG-primer 5'-AGT GAA GGA ATC GCT TTC CG-3' (derived from EMBL AB005520) followed by digestion with $H p a I I$. All restriction enzyme digests were separated on $4 \%$ agarose gels.

Fig. 1. Schematic presentation of identified PGC-1 variants and approximate positions relative to known functional domains. LXXLL, recognition site (LXXLL motif); PKAP, protein kinase A phosphorylation consensus site; SRD, serine and arginine rich domain; RRM, RNA recognition motif
Statistical analysis. Fisher's exact test was applied to examine differences in allele frequencies between diabetic and non-diabetic subjects. A general linear model was used to test variables (or transformed variables) for differences between genotype groups. Genotype and gender were considered as fixed factors and age and BMI as covariates. A $p$-value of less than 0.05 was considered significant. All analyses were done using Statistical Package for Social Science (SPSS, Chicago. Ill., USA) version 10.0. The genotype relative risk (GRR) was estimated by logistic regression from the genotype data using a log-additive model for the risk. Test for additivity gave a likelihood ratio statistic of 0.285 on $1 \mathrm{df}(p=0.593)$. Interaction between the Pro12Ala polymorphism of PPAR- $\gamma 2$ and the Gly482Ser polymorphism of $P G C-1$ was tested using logistic regression.

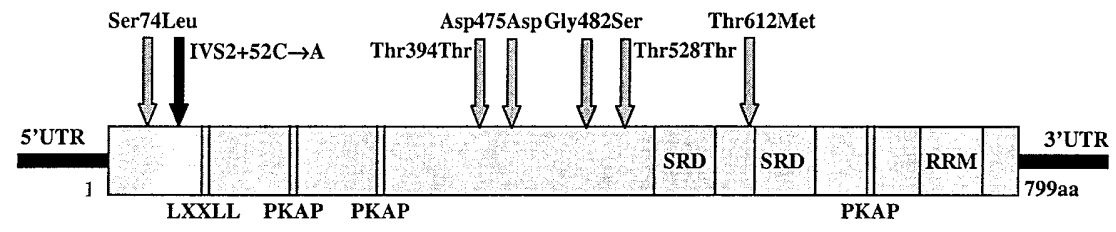


Table 2. Genotype and allele frequencies of the examined variants in the PGC-1 gene in Type II diabetic patients and glucose tolerant subjects

\begin{tabular}{|c|c|c|c|c|c|c|c|c|c|}
\hline & \multicolumn{3}{|c|}{ Initial association study } & \multicolumn{3}{|c|}{ Replication study } & \multicolumn{3}{|c|}{ Combined study } \\
\hline & $\begin{array}{l}\text { Type II } \\
\text { diabetic } \\
\text { patients }\end{array}$ & $\begin{array}{l}\text { Glucose- } \\
\text { tolerant } \\
\text { subjects }\end{array}$ & $p$ & $\begin{array}{l}\text { Type II } \\
\text { diabetic } \\
\text { patients }\end{array}$ & $\begin{array}{l}\text { Glucose- } \\
\text { tolerant } \\
\text { subjects }\end{array}$ & $p$ & $\begin{array}{l}\text { Type II } \\
\text { diabetic } \\
\text { subjects }\end{array}$ & $\begin{array}{l}\text { Glucose- } \\
\text { tolerant } \\
\text { subjects }\end{array}$ & $p$ \\
\hline \multicolumn{10}{|l|}{ Ser 74Leu } \\
\hline Ser/Ser & $466(99)$ & $197(99)$ & & $223(99)$ & $290(99)$ & & $689(99)$ & 487 (99) & \\
\hline Ser/Leu & $3(1)$ & $1(1)$ & & $2(1)$ & $2(1)$ & & $5(1)$ & $3(1)$ & \\
\hline Leu/Leu & $0(0)$ & $0(0)$ & $1.0^{\mathrm{a}}$ & $0(0)$ & $0(0)$ & $1.0^{\mathrm{a}}$ & $0(0)$ & $0(0)$ & $1.0^{\mathrm{a}}$ \\
\hline \multicolumn{10}{|l|}{$I V S 2+52 C \rightarrow A$} \\
\hline$C / C$ & $178(37)$ & $62(30)$ & & $74(33)$ & $107(37)$ & & $252(36)$ & $169(34)$ & \\
\hline$C / A$ & $221(46)$ & $102(50)$ & & $110(49)$ & $142(49)$ & & $331(47)$ & $244(49)$ & \\
\hline$A / A$ & 79 (17) & $40(20)$ & $0.2^{\mathrm{a}}$ & 39 (17) & $42(14)$ & $0.5^{\mathrm{a}}$ & $118(17)$ & $82(17)$ & $0.8^{\mathrm{a}}$ \\
\hline Allele frequency & $\begin{array}{l}39.6 \\
(36.6-42.7)\end{array}$ & $\begin{array}{l}44.6 \\
(39.8-49.4)\end{array}$ & 0.09 & $\begin{array}{l}42.2 \\
(37.6-46.7)\end{array}$ & $\begin{array}{l}38.8 \\
(34.9-42.8)\end{array}$ & 0.3 & $\begin{array}{l}40.4 \\
(37.9-43.0)\end{array}$ & $\begin{array}{l}41.2 \\
(38.1-44.3)\end{array}$ & 0.7 \\
\hline \multicolumn{10}{|l|}{ Thr612Met } \\
\hline Thr/Thr & $443(93)$ & $183(90)$ & & $211(96)$ & $260(89)$ & & $654(94)$ & $443(90)$ & \\
\hline Thr/Met & $31(7)$ & $20(10)$ & & $9(4)$ & $31(11)$ & & $40(6)$ & $51(10)$ & \\
\hline Met/Met & $1(0)$ & $0(0)$ & $0.2^{\mathrm{a}}$ & $0(0)$ & $0(0)$ & $0.007^{\mathrm{a}}$ & $1(0)$ & $0(0)$ & $0.005^{\mathrm{a}}$ \\
\hline Allele frequency & $3.5(2.3-4.6)$ & $4.9(2.8-7.0)$ & 0.2 & $2.1(0.7-3.0)$ & $5.3(3.5-7.2)$ & 0.009 & $3.0(2.1-3.9)$ & $5.2(3.8-6.5)$ & 0.01 \\
\hline
\end{tabular}

Data are number of subjects with each genotype (\% of each group) and allele frequencies of minor allele in \% (95\%-CI). The $p$ values compare genotype distribution $\left({ }^{\mathrm{a}}\right)$ and allele frequencies between Type II diabetic patients and glucose tolerant subjects

\section{Results}

The mutation screening covered the coding region of $P G C-1$. In the 53 Type II diabetic patients, we identified a total of 7 different variants (Fig.1): Ser74Leu (identified in 2 out of 53 patients, nucleotide position 341: TCA $\rightarrow$ TTA $), \quad I V S 2+52 C \rightarrow A \quad(19$ patients $)$, Thr394Thr (11 patients, 1302: ACG $\rightarrow$ ACA), Asp475Asp (13 patients, 1545: GAC $\rightarrow$ GAT), Gly482Ser (24 patients, 1564: GGT $\rightarrow$ AGT), Thr528Thr (37 patients, 1704: ACA $\rightarrow$ ACG), and Thr612Met (3 patients, 1955: ACG $\rightarrow$ ATG). The variants were further examined in an association study comprising 483 Type II diabetic patients and 216 glucose-tolerant control subjects and in a replication study comprising 201 Type II diabetic patients and 293 glucose-tolerant control subjects. All variants were in Hardy-Weinberg equilibrium. The allele frequencies of the Ser74Leu, IVS $2+52 C \rightarrow A$, Asp 475Asp, and Thr528Thr variants did not differ significantly between diabetic and non-diabetic subjects (Table 2 and data not shown). The common Gly-allele of codon 482 and the common $\mathrm{C}$-allele of the intronic variant segregated together (disequilibrium coefficient $\mathrm{D}=0.04$ ). The allele frequencies of the Ser74Leu and Thr612Met variants were not sufficiently high to provide reliable estimates of linkage disequilibrium with the Gly482$\mathrm{Ser}$ polymorphism. The minor Ser-allele of codon
482 and the minor Asp-allele of codon 475 (allele frequencies: NGT subjects, 5.6\%; diabetic patients, $8.6 \%)$ segregated together $(\mathrm{D}=-0.02)$. The common Thr528Thr substitution allele (NGT subjects, 38.5\%; diabetic patients, $45.3 \%$ ) segregated with the Ser-allele of codon $482(\mathrm{D}=0.21)$. The minor Ser-allele of codon 482 and the minor Thr-allele of codon $394 \mathrm{seg}$ regated together $(\mathrm{D}=-0.07)$.

The allele frequency of the Gly482Ser variant was higher among Type II diabetic patients compared to glucose-tolerant subjects $(37.0 \%$ vs $30.8 \%$, $p=0.032$ ) (Table 2). In a replication study the differences in allele frequencies remained significant (38.1\% vs $30.4 \%, p=0.0135)$. The combined study yielded an allelic frequency of $37.3 \%$ for the Type II diabetic patients and $30.5 \%$ for the glucose-tolerant subjects $(p=0.0007)$. The genotype relative risk for diabetes was estimated to 1.34 (95\%-CI: 1.13-1.59) corresponding to a population attributable risk of $18 \%$. In the combined group of diabetic subjects, carriers of the Gly482Ser polymorphism did not differ significantly from wildtype carriers in clinical or biochemical values including age of diabetes onset, BMI, waist circumference, treatment, degree and prevalence of micro- and macrovascular complications, $\mathrm{HbA}_{1 \mathrm{C}}$ or fasting serum lipids (data not shown). Moreover, in the glucose-tolerant subjects there was no evidence of a relation between 
Table 3. Clinical and biochemical characteristics of two normal glucose-tolerant Danish Caucasian study samples classified according to PGC-1 Gly482Ser genotype

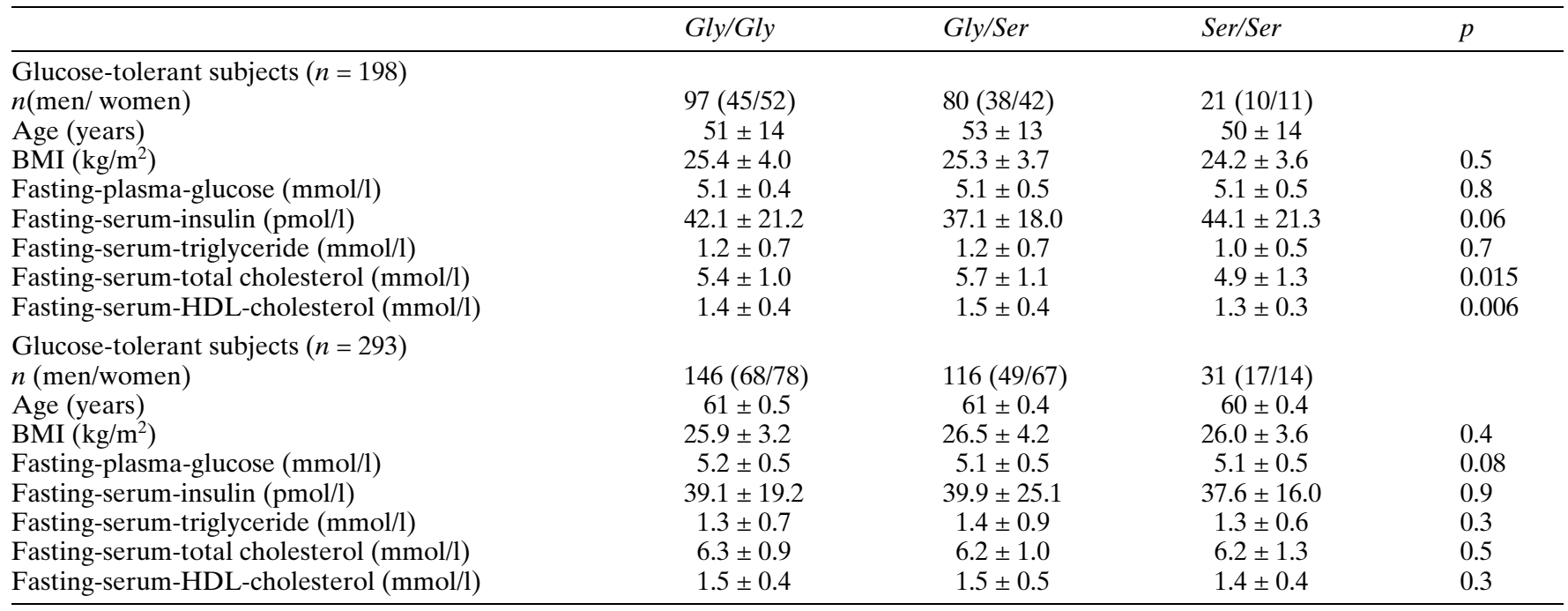

Data are means \pm standard deviation. Values of insulin were logarithmically transformed. $p$ values were adjusted for age, gender, and BMI

Table 4. Distribution of genotypes defined by the Gly482Ser variant of PGC-1 and the Prol2Ala variant of PPAR- 2 among Type II diabetic patients and glucose tolerant subjects

\begin{tabular}{|c|c|c|c|c|c|c|}
\hline \multirow{2}{*}{$\begin{array}{l}\text { PPAR- } \gamma 2 \text { Pro12Ala genotype } \\
\text { PGC-1 Gly482Ser genotype }\end{array}$} & \multicolumn{3}{|c|}{ Protective $P P A R-\gamma 2$ variant $A l a / X$} & \multicolumn{3}{|c|}{ Diabetogenic $P P A R-\gamma 2$ variant Pro/Pro } \\
\hline & Gly/Gly & Gly/Ser & $\mathrm{Ser} / \mathrm{Ser}$ & Gly/Gly & Gly/Ser & Ser/Ser \\
\hline Type II diabetic patients & $43(41)$ & $48(46)$ & $13(13)$ & $134(42)$ & $140(43)$ & $48(15)$ \\
\hline
\end{tabular}

Data are number of subjects with each genotype combination (\% of each group). A test for synergistic effect for risk of Type II diabetes using logistic regression was not significant $(p=0.7)$

the codon 482 variant and estimates of BMI, waist circumference, fasting serum triglycerides, plasma free fatty acids or plasma glucose, serum insulin and serum C-peptide in the fasting state or during an OGTT (Table 3 and data not given). There was a strong association of the Gly482Ser variant with fasting serum total and HDL-cholesterol $(p=0.015$ and $p=0.006$, respectively) in the initial study. However, this association was not observed in the replication study (Table 3).

When stratifying the examined study population according to the Gly482Ser genotype for Pro12Ala genotype of $P P A R-\gamma 2$ the genotype distribution and allele frequencies of the Ser-allele in relation to Type II diabetes remained unchanged (Table 4). No interaction of the two polymorphisms on risk of Type II diabetes was observed $(p=0.7)$.

The allele frequency of the Thr612Met variant was lower among Type II diabetic patients than among normal glucose-tolerant control subjects in the replication study $(2.1 \%$ vs $5.3 \%, p=0.009)$ but not in the initial study $(3.5 \%$ vs $4.9 \%, p=0.2)$ (Table 2$)$. The combined study yielded an allele frequency of $3.0 \%$ among Type II diabetic patients and 5.2\% among glucose-tolerant control subjects $(p=0.01)$. The genotype relative risk for diabetes was estimated to 0.57 (95\%-CI: $0.37-0.86)$. In the combined group of diabetic subjects, carriers of the Thr612Met variant did not differ significantly from wildtype carriers in clinical or biochemical values (data not shown). Moreover, in the glucose-tolerant subjects there was no evidence of a relation between the codon 612 variant and clinical or biochemical estimates (data not shown).

The allele frequency of the Ser74Leu and the $I V S 2+52 C \rightarrow A$ variants were not statistically different between diabetic and control subjects (Table 2). The allele frequencies of the Thr394Thr variant did not differ significantly between diabetic and non-diabetic subjects in the initial study $(19.8 \%$ vs $23.4 \%$, $p=0.1)$ or in the replication study $(19.7 \%$ vs $24.3 \%$, $p=0.08)$. However, in the combined study the allele frequency was lower among Type II diabetic patients compared to glucose-tolerant control subjects $(19.7 \%$ vs. $23.9 \%, p=0.02)$ (data not shown). 


\section{Discussion}

There is extensive circumstantial evidence from family investigations including studies in twins and from studies of hybrid populations descended from highrisk and low-risk ancestral populations in favour of genetic determinants for the common late onset form of Type II diabetes. It is also likely that Type II diabetes in many cases is polygenic and it is suggested that subsets of patients display changes in various diabetes susceptibility genes thereby adding to the heterogeneity of Type II diabetes.

Among the few Type II diabetes susceptibility gene variants, which have been reproducibly reported to be associated with Type II diabetes are the Pro12Ala polymorphism of PPAR- $\gamma$ and polymorphisms in the CAPN10 gene, the SUR gene, and the KIR6.2 gene [10-20]. In a study of more than 3000 subjects the common Pro-allele of PPAR- $\gamma 2$ has been shown to confer a 1.25-fold increase in risk of Type II diabetes [12]. The diabetogenic effect of this variant appears to be mediated through a weak impairment of whole body insulin sensitivity $[10,11]$. These findings prompted us to examine the $P G C-1$ gene for variability, which might be associated with Type II diabetes because PGC-1, besides being a coactivator of PPAR- $\gamma$ and $-\alpha$, has a critical role in glucose uptake and adaptive thermogenesis [1]. Only one out of seven tested gene variants - the Gly482Ser polymorphism - showed nominal allelic association in the initial association study. Testing of this variant in a replication sample confirmed the association of the polymorphism to Type II diabetes. Combining the initial and the replication samples showed a 1.34fold increase in diabetes risk associated with the Serallele of Gly482Ser. Although this diabetes-susceptibility effect seems to be small, it translates into a considerable population attributable risk of $18 \%$ due to the high frequency of the risk allele.

In this study, we failed to relate the Gly482Ser polymorphism to subphenotypes like BMI, waist circumference, plasma glucose, serum insulin and serum C-peptide during an OGTT in the glucose tolerant subjects. Similarly, we were not able to associate the $P G C-1$ variant with biochemical and anthropometric characteristics or age of clinical disease onset in the two groups of diabetic subjects. However, in the initial study of glucose-tolerant subjects we did observe a significant association of the Gly482Ser polymorphism with fasting serum cholesterol levels, which could be consistent with the role of PGC-1 as a coactivator of PPAR- $\alpha$, in which genetic variability confers alterations in circulating cholesterol levels [21].

Even though the $P G C-1$ Gly482Ser variant is associated with Type II diabetes in the examined populations this variant might not be the causative polymorphism but could be in linkage disequilibrium with an as yet unidentified aetiological variant. Gly482Ser is located in a part of the protein whose function is not known and glycine at residue 482 is not conserved between human beings and mice. However, a recent study showed that residues $403-570$ of PGC-1 are critical for its interaction with MEF2C and thereby the ability of PGC-1 to restore insulin sensitive GLUT4 expression [4].

Intriguingly, homozygosity for the intronic variant $I V S 2+52 C \rightarrow A$ of the $P G C-1$ gene has been reported to be associated with a decrease in age-adjusted and sex-adjusted BMI in a study of 964 American Caucasian subjects suggesting that this noncoding variant could act protectively against fat accumulation [22]. Because stimulation of the $\beta-3$ adrenergic receptor $(\beta 3 \mathrm{AR})$ has been shown to induce PGC-1 expression $[2]$, the same authors also tested the interaction between the intronic PGC-1 variant and the Trp64Arg variant in $\beta 3 A R$ [22], which has been shown to be associated with features of the metabolic syndrome [23-25]. They found that the IVS2 +52C $\rightarrow A$ variant of $P G C-1$ decreased the odds of obesity in the absence of the Arg-allele but not in the presence of the Arg-allele. In this study, the $I V S 2+52 C \rightarrow A$ variant was not associated with Type II diabetes nor was homozygosity of the variant associated with a higher BMI in the diabetic or the normal glucose-tolerant subjects.

In the initial association study, the Thr612Met variant was not associated with Type II diabetes. In contrast, the variant was found to be associated with Type II diabetes both in the replication study and in the combined study. It is not clear whether this observation is due to linkage disequilibrium with the Gly482Ser variant or whether it is a true functional variant providing a reduced risk of developing Type II diabetes or a chance finding due to multiple testing of various gene variants. Thr612Met is located in a part of the protein whose function is not known and is conserved between human beings and mice.

In this study a test for interaction between the Gly482Ser variant and the Pro12Ala variant in $P P A R-\gamma 2$ gave no indication for additive effects on diabetes status. However, due to the polygenic nature of the common forms of Type II diabetes, future studies should examine the potential interactions of the PGC-1 Gly482Ser, PPAR- $\gamma$ Pro12Ala and $\beta 3 A R$ Trp64Arg polymorphisms to see if they have additive or synergistic impact on the susceptibility to common subsets of Type II diabetes mellitus.

Acknowledgements. The authors would like to thank A. Forman, L. Aabo, I. L. Wantzin, and C. B. P. Søholm for their dedicated technical assistance, and G. Lademann for secretarial support. The study was supported by the Danish Medical Research Council, the Danish Diabetes Association, the Danish Heart Foundation, the Velux Foundation, and EEC (BMH4CT98-3084 and QLRT-CT-1999-00546). 


\section{References}

1. Puigserver P, Wu Z, Park CW, Graves R, Wright M, Spiegelman BM (1998) A cold-inducible coactivator of nuclear receptors linked to adaptive thermogenesis. Cell 92: 829-839

2. Wu Z, Puigserver P, Andersson U et al. (1999) Mechanisms controlling mitochondrial biogenesis and respiration through the thermogenic coactivator PGC-1. Cell 98: 115-124

3. Vega RB, Huss JM, Kelly DP (2000) The coactivator PGC1 cooperates with peroxisome proliferator-activated receptor- $\alpha$ in transcriptional control of nuclear genes encoding mitochondrial fatty acid oxidation enzymes. Mol Cell Biol 20: $1868-1876$

4. Michael LF, Wu Z, Cheatham B et al. (2001) Restoration of insulin-sensitive glucose transporter (GLUT4) gene expression in muscle cells by the transcriptional coactivator PGC-1. Proc Natl Acad Sci USA 98: 3820-3825

5. Larrouy D, Vidal H, Andreelli F, Laville M, Langin D (1999) Cloning and mRNA tissue distribution of human PPAR- $\gamma$ coactivator-1. Int J Obes 23: 1327-1332

6. Esterbauer H, Oberkofler H, Krempler F, Patsch W (1999) Human peroxisome proliferator activated receptor gamma coactivator 1 (PPARGC1) gene: cDNA sequence, genomic organization, chromosomal localization, and tissue expression. Genomics 62: 98-102

7. Pratley RE, Thompson DB, Prochazka M et al. (1998) An autosomal genomic scan for loci linked to prediabetic phenotypes in Pima Indians. J Clin Invest 101: 1757-1764

8. Alberti KG, Zimmet PZ (1998) Definition, diagnosis and classification of diabetes mellitus and its complications. Part 1: diagnosis and classification of diabetes mellitus provisional report of a WHO consultation. Diabet Med 15: 539-553

9. Hansen T, Andersen CB, Echwald SM et al. (1997) Identification of a common amino acid polymorphism in the p85- $\alpha$ regulatory subunit of phosphatidylinositol 3-kinase: effects on glucose disappearance constant, glucose effectiveness, and the insulin sensitivity index. Diabetes 46: 494-501

10. Deeb SS, Fajas L, Nemoto M et al. (1998) A Pro12Ala substitution in PPAR $\gamma 2$ associated with decreased receptor activity, lower body mass index and improved insulin sensitivity. Nat Genet 20: 284-287

11. Hara K, Okada T, Tobe K et al. (2000) The Pro12Ala polymorphism in PPAR $\gamma 2$ may confer resistance to type 2 diabetes. Biochem Biophys Res Commun 271: 212-216

12. Altshuler D, Hirschhorn JN, Klannemark M et al. (2000) The common PPAR $\gamma$ Pro12Ala polymorphism is associated with decreased risk of type 2 diabetes. Nat Genet 26: 76-80

13. Douglas JA, Erdos MR, Watanabe RM et al. (2001) The peroxisome proliferator-activated receptor- $\gamma 2$ Pro12Ala variant. Association With Type II Diabetes and Trait Differences. Diabetes 50: 886-890

14. Mori H, Ikegami H, Kawaguchi Y et al. (2001) The Pro $^{12} \rightarrow$ Ala substitution in PPAR- $\gamma$ is associated with resistance to development of diabetes in the general population. Diabetes 50: 891-894

15. Horikawa Y, Oda N, Cox NJ et al. (2000) Genetic variation in the gene encoding calpain-10 is associated with type 2 diabetes mellitus. Nat Genet 26: 163-175

16. Inoue H, Ferrer J, Welling CM et al. (1996) Sequence variants in the sulfonylurea receptor (SUR) gene are associated with NIDDM in Caucasians. Diabetes 45: 825-831

17. Hani EH, Clement K, Velho G et al. (1997) Genetic studies of the sulfonylurea receptor gene locus in NIDDM and in morbid obesity among French Caucasians. Diabetes 46: 688-694

18. Hansen T, Echwald SM, Hansen L et al. (1998) Decreased tolbutamide-stimulated insulin secretion in healthy subjects with sequence variants in the high-affinity sulfonylurea receptor gene. Diabetes 47: 598-605

19. Hart LM, de Knijff P, Dekker JM et al. (1999) Variants in the sulphonylurea receptor gene: association of the exon 16-3t variant with Type II diabetes mellitus in Dutch Caucasians. Diabetologia 42: 617-620

20. Hani EH, Boutin P, Durand E et al. (1998) Missense mutations in the pancreatic islet beta cell inwardly rectifying $\mathrm{K}^{+}$ channel gene (KIR6.2/BIR): a meta-analysis suggests a role in the polygenic basis of Type II diabetes mellitus in Caucasians. Diabetologia 41: 1511-1515

21. Flavell DM, Torra IP, Jamshidi Y et al. (2000) Variation in the PPAR alpha gene is associated with altered function in vitro and plasma lipid concentrations in Type II diabetic subjects. Diabetologia 43: 673-680

22. Fan Z, Pollin TI, Gong D et al. (2000) Association of an intronic variant of peroxisome proliferator-activated receptor- $\gamma$ coactivator-1 (PGC-1) with decreased body mass index (BMI) in Caucasians and interaction with the Trp64Arg variant of the $\beta$-3 adrenergic receptor. Am J Hum Genet 67: 234 (Abstract)

23. Widen E, Lehto M, Kanninen T, Walston J, Shuldiner AR, Groop LC (1995) Association of a polymorphism in the $\beta_{3}$-adrenergic-receptor gene with features of the insulin resistance syndrome in Finns. N Engl J Med 333: 348-351

24. Clement K, Vaisse C, Manning BS et al. (1995) Genetic variation in the $\beta_{3}$-adrenergic receptor and an increased capacity to gain weight in patients with morbid obesity. N Engl J Med 333: 352-354

25. Kadowaki H, Yasuda K, Iwamoto K et al. (1995) A mutation in the $\beta_{3}$-adrenergic receptor gene is associated with obesity and hyperinsulinemia in Japanese subjects. Biochem Biophys Res Commun 215: 555-560 